\title{
High-Temperature X-Ray Diffraction Apparatus
}

\author{
By Alvin Van Valkenburg, Jr., and Howard F. McMurdie
}

\begin{abstract}
A furnace for obtaining X-ray powder diffraction patterns of samples at elevated temperatures has been designed and constructed. This furnace is used with the Norelco $\mathrm{X}$-ray spectrometer, in which the photographic film is replaced by a Geiger counter. The assembly has the following advantages over previously described high-temperature X-ray powder diffraction cameras: (1) Any number of patterns can be obtained without intermediate cooling of the sample, (2) in 40 minutes the pattern is produced in a form ready for study, and (3) patterns can be obtained at temperatures up to $1,500^{\circ} \mathrm{C}$. The diffraction data for the $\alpha$ form of $2 \mathrm{CaO} . \mathrm{SiO}_{2}$ are given.
\end{abstract}

\section{Introduction}

Many crystalline substances exhibit structure changes on heating, different modifications being stable at different temperatures. The method most commonly used to investigate modifications that are unstable at room temperatures is to hold a specimen at a temperature above an inversion and quench. In many cases, the form stable at the higher temperature is thereby preserved for examination at room temperature and can be studied by X-ray diffraction or optical methods. Unfortunately, some substances revert on quenching to the original form. Therefore, a determination at high temperature must be made while the specimen is held at an elevated temperature.

For this reason, and also to study in greater detail the processes of inversion, it is desirable to have equipment by which X-ray diffraction patterns can be made at elevated temperatures.

Various cameras have been designed for such work $[1,2,3,4]^{1}$, but in general they have been confined to temperatures below $800^{\circ}$ C. For work in ceramics, and particularly in refractories, it is often desirable to study changes that take place at temperatures appreciably higher. Patterns obtained at elevated temperatures were reported in Germany [5], but details of the furnace

\footnotetext{
${ }^{1}$ Figures in brackets indicate the literature references at the end of this paper.
}

are lacking. One factor that has prevented the use of higher temperatures is the problem of cooling the photographic film. H. Friedman's development [6] of an X-ray powder diffraction apparatus using a Geiger counter in place of a film and its commercial production have helped solve this problem. ${ }^{2}$ This apparatus covers the arc from 45 to 5 degrees of Bragg angle in 40 minutes, the pattern being recorded on a strip chart with 1 inch equal to 1 degree. Either $\mathrm{Cu}$ or Fe radiation can be used.

In the present paper, a furnace for use with the Geiger-counter X-ray spectrometer is described. With this equipment, X-ray powder diffraction patterns can be made on samples at temperatures up to $1,500^{\circ} \mathrm{C}$.

\section{Construction of furnace}

The furnace, cylindrical in shape and heated electrically, is mounted midway between the X-ray tube and the Geiger counter (figs. 1 and 2). The brass base $(G$, fig. 3 ) is inserted in place of the specimen holder supplied regularly with the X-ray spectrometer. This base (or platform) has a central recessed area for an Alundum disk and pedestal ( $F$, fig. 3$)$ that supports the 80 -percentplatinum-20-percent-rhodium specimen holder $(E$,

${ }^{2}$ This equipment is made available commercially by the North American Philips Co. 


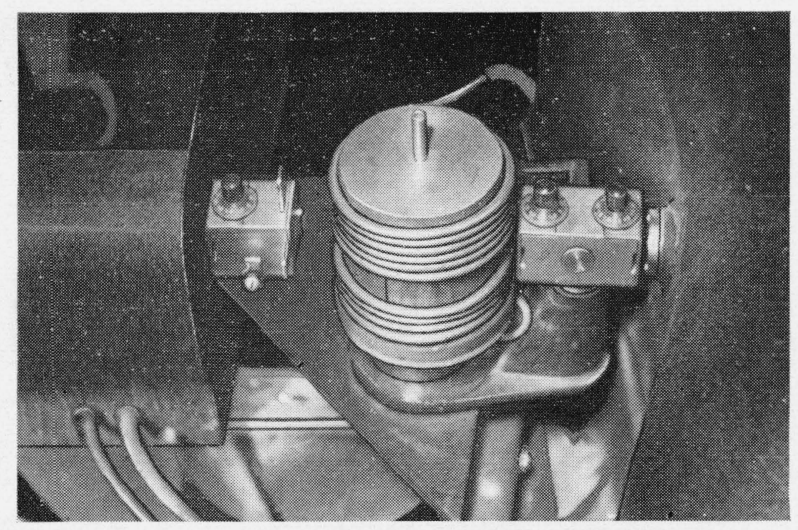

Figure 1.-Over-all view of furnace in place in X-ray spectrometer.

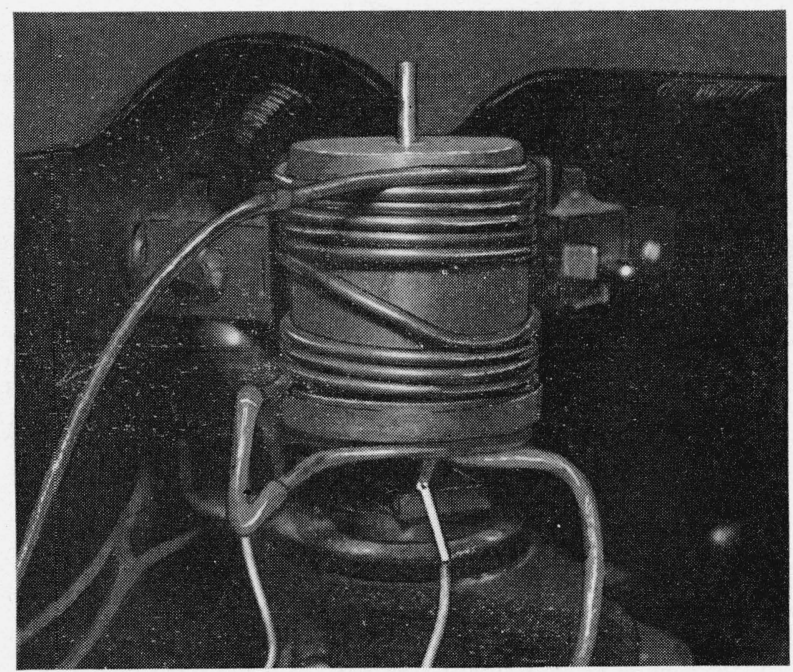

Figure 2.-Furnace in place.

figs. 3, and 4). This specimen holder has a groove in the base, which fits a ridge on the ceramic pedestal, thereby assuring correct alinement of the holder. Surrounding the ceramic pedestal and specimen holder are a two-unit heating element ( $D$, fig. 3$)$ and two shields ( $B$ and $C$, fig. 3) which are alined by grooves in the ceramic base (fig. 5), and a third shield (A, fig. 3) which is alined by a groove in base, $G$.

The heating element consists of an 80-percentplatinum-20-percent-rhodium wire winding on two coaxial Alundum tubes, which have windows cut in them at the specimen level for transmission of the X-ray beam. These tubes are shown separated in figure 6 . The wire is placed in grooves on the outside of each tube. The inner tube at the window level has an additional opening cut in the rear and, in the front, that part of the tube between the windows has the winding placed on both sides. The outer tube at the window level has the winding doubled back on the rear section of tube. These windings at the window level, combined with the opening cut into the rear of the inner tube, give direct radiation to the front and rear of the platinum specimen holder. The two sets of windings are connected in series. The heating element is shown in place on the base in figure 7 .

The innermost of the three shields $(C$, figs. 3 and 8 ) is a radiating shield of 80 -percent platinum20-percent-rhodium; the intermediate shield ( $B$, figs. 1 and 8 ) is made of stainless steel; the third shield ( $A$, figs. 1 and 8 ) forms the outer shell and is made of brass. Each shield contains two openings for X-ray transmission at the specimen level. The windows of the outer shell are covered with thin sheets of beryllium ( $I$, fig. 3 ) to prevent heat radiation to adjacent parts and to minimize air currents within the furnace. Water-cooling

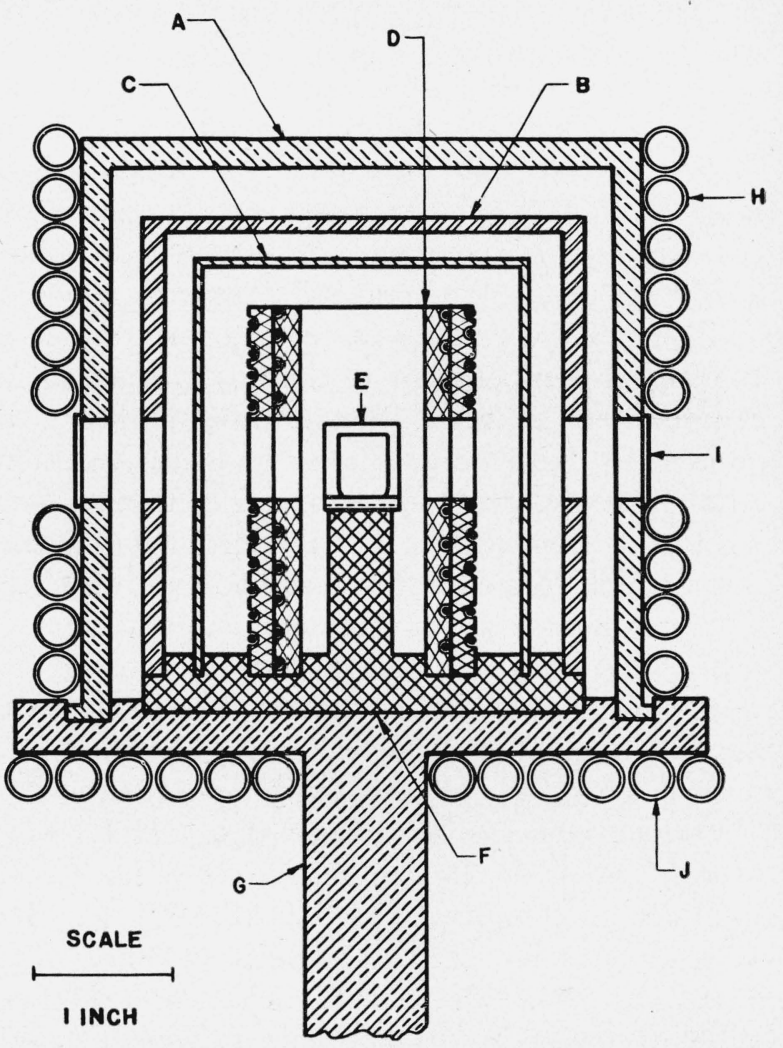

Figure 3.-Cross section of $X$-ray diffraction furnace.

$A$, Brass outer shell; $B$, intermediate steel shield; $C$, platinum radiation shield; $D$, heating unit with platinum windings; $E$, specimen holder $(80 \%$ Pt-20\% Rh); $F$, ceramic base; $G$, brass base; $H$, water-cooling coil; $I$, beryllium cover to window; $J$, water-cooling coil. 

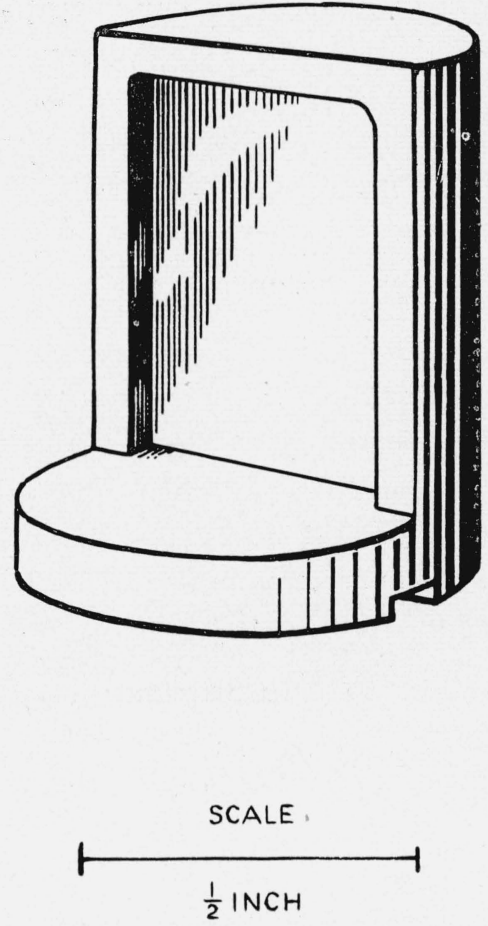

Figure 4.-Specimen holder. 80 percent $\mathrm{Pt}-20$ percent Rh.

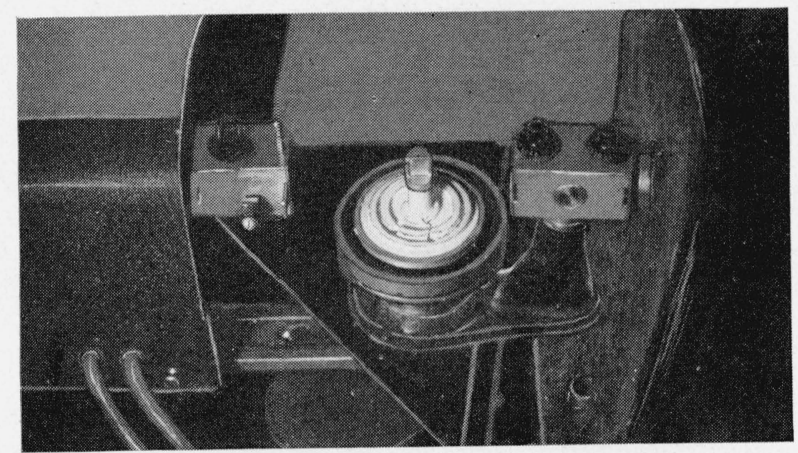

Figure 5.-Ceramic base and specimen holder.
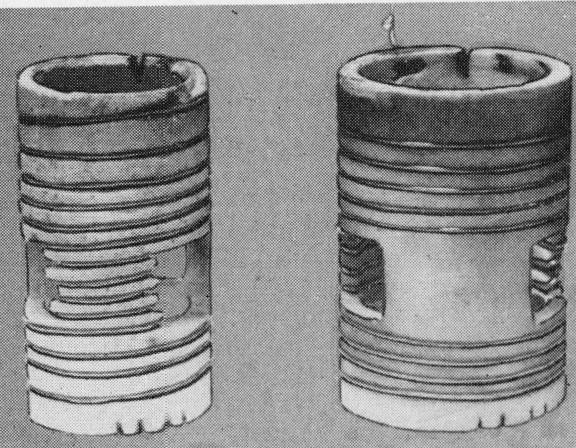

Figure 6.-Heating elements separated.

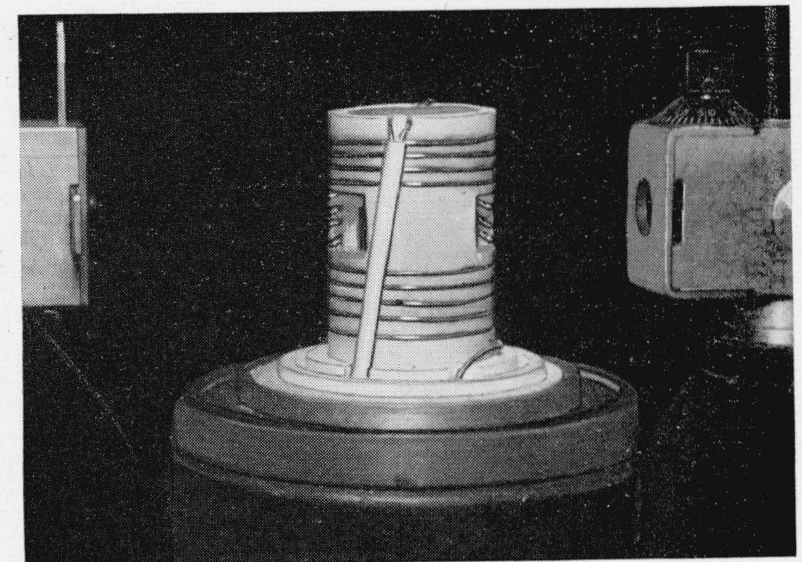

FigURE 7.-Heating element on ceramic base, showing thermocouple leads.

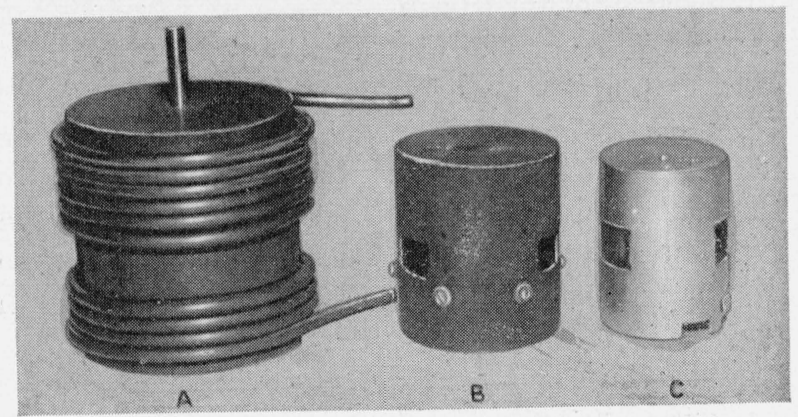

Figure 8.- Shields.

$A$, Outer brass case with cooling coil; $B$, intermediate steel shield; $C$, platinum radiation shield.

coils placed beneath the brass base and around the outer shell are indicated by $J$ and $H$ in figure 3 and shown in figure 2 .

The furnace is heated with $110-\mathrm{v}$ alternatingcurrent controlled by two variable autotransformers so that the secondary of the first feeds the primary of the second. At $1,500^{\circ} \mathrm{C}$ the furnace requires about $12 \mathrm{amp}$ at $60 \mathrm{v}$. The furnace is maintained automatically within $\pm 1 \mathrm{deg}$ C.

The temperature of the furnace is measured and controlled by a platinum-10-percent-rhodium thermocouple connected to an electronic-recording potentiometer. The wires are enclosed in a ceramic tube placed vertically alongside the heating element (fig. 7). At the top of the heating element, the bare thermocouple wires are bent over the edge, and the junction is directly in front of the specimen holder.

The following simple procedures are necessary to prepare the furnace for operation: (a) Removing the three shields, $A, B$, and $C$; (b) setting the 
specimen holder, $E$, with the powdered sample pressed into the recessed face, upon the pedestal, and (c) replacing the shields. Parts $G, F$, and $D$ do not need to be disturbed.

An X-ray spectrometer equipped with a furnace like the one described has the advantage that the pattern is available for inspection at once without the necessity of photographic processing. Also, a second pattern at a different temperature can be made immediately without cooling the sample to room temperature.

\section{High-Temperature Form of $2 \mathrm{CaO} \cdot \mathrm{SiO}_{2}$}

Thermal studies have shown that a change takes place at about $1,420^{\circ} \mathrm{C}$ in $2 \mathrm{CaO}^{-\mathrm{SiO}_{2}}$ [7]. However, material quenched from above $1,500^{\circ} \mathrm{C}$ does not give an X-ray pattern different from $\beta-2 \mathrm{CaOSiO}_{2}$. Bredig [8], by analogy with $\mathrm{K}_{2} \mathrm{PO}_{4}$, postulated that $\alpha-2 \mathrm{CaO} . \mathrm{SiO}_{2}$ must be hexagonal with an axial ratio of about 1.29. Greene [9] was able to quench an impure $2 \mathrm{CaO} \cdot \mathrm{SiO}_{2}$ (with $\mathrm{Al}_{2} \mathrm{O}_{3}$ and $\mathrm{Na}_{2} \mathrm{O}$ present) and obtain a sample that gave an $\mathrm{X}$-ray pattern indicating a hexagonal cell with $A=5.44 \mathrm{kX}$ and $C=7.02 \mathrm{kX}$.

With the equipment described in this paper, a pattern of pure $2 \mathrm{CaO} \cdot \mathrm{SiO}_{2}$ was obtained at $1,500^{\circ}$ C. The data given in table 1 agree with the data from the impure sample used by Greene. This shows that $\alpha-2 \mathrm{CaO} . \mathrm{SiO}_{2}$ is hexagonal, isostructural with $\mathrm{K}_{2} \mathrm{PO}_{4}$ and with $A=5.08 \mathrm{kX}$ and $C=7.05 \mathrm{kX}$.
TABLE 1.-Diffraction data for $2 \mathrm{CaO}^{\mathrm{S}} \mathrm{SiO}_{2}$ at $1,500^{\circ} \mathrm{C}$

\begin{tabular}{|c|c|c|}
\hline$h k l$ & $d / n$ & $\begin{array}{l}\text { Relative } \\
\text { intensity }\end{array}$ \\
\hline 102 & $\begin{array}{r}k X \\
2.84\end{array}$ & $\begin{array}{c}\text { Percent } \\
85\end{array}$ \\
\hline 110 & 2. 69 & 100 \\
\hline $201 \ldots$ & 2.25 & 30 \\
\hline $202 \ldots$ & 1.970 & 55 \\
\hline 122 & 1. 603 & 15 \\
\hline (2) & 1.576 & 15 \\
\hline 114 & 1.501 & 8 \\
\hline - & 1. 368 & 3 \\
\hline 132 & 1. 280 & 2 \\
\hline
\end{tabular}

The authors thank L. G. Cossette for his help in preparing the ceramic base and for his help and suggestions on winding the heating coil.

\section{References}

[1] A. H. Jay, Z. Krist. 86, 106 (1933).

[2] L. Backhurst, Proc. Roy. Soc. (London) [A] 102, 340 (1923).

[3] A. Westman and G. Pragmen, Z. physik. Chem. [B] 102, 1 (1922).

[4] M. J. Buerger, N. W. Buerger, and F. G. Chesley, Am. Mineral. 28, 288 (1943).

[5] Otto Raff and Fritz Ebert, Z. anorg. allgem. Chem. 180, 19 (1929).

[6] H. Friedman, Electronics 18, 132 (1945).

[7] A. A. Rankin and F. E. Wright, Am. J. Sci. [4] 39, 1 (1915).

[8] M. A. Bredig, J. Phys. Chem. 46, 747 (1942).

[9] K. T. Greene, J. Research NBS 32, 1 (1944) RP1570.

Washington, January 23, 1947. 